Prevalence of childhood extrafamilial victimization

RUNNING HEAD: Prevalence of childhood extrafamilial victimization

The prevalence of childhood victimization experienced outside of the family: findings from an English prevalence study.

\author{
Vicki Jackson, $\mathrm{PhD}^{\mathrm{a}}$ \\ Kevin Browne, $\mathrm{PhD}^{\mathrm{a}}$ \\ Stephen Joseph, $\mathrm{PhD}^{\mathrm{b}}$
}

${ }^{\mathrm{a}}$ Centre for Forensic and Family Psychology, Division of Psychiatry and Applied

Psychology, University of Nottingham, YANG Fujia Building, Jubilee Campus, Wollaton Road, Nottingham, NG8 1BB, UK

${ }^{b}$ Faculty of Social Sciences, University of Nottingham, Dearing Building, Jubilee Campus, Wollaton Road, Nottingham, NG8 1BB,UK

Corresponding author: Vicki Jackson, vicki_jackson_1@ @hotmail.com 
Prevalence of childhood extrafamilial victimization

\begin{abstract}
There has been little research carried out in the United Kingdom (UK) aimed at providing a holistic exploration of the victim experiences of young people within the school and community environments (extrafamilial victimization). This study therefore examined the prevalence of 24 different types of extrafamilial victimization experienced by a sample of 730 young people, aged 13 to 16 years (mean 13.8 years), from one county in the UK. The findings show that the vast majority of young people experienced some form of extrafamilial victimization over their lifetime (84.1\%) and past year (67.2\%). Looking at individual categories of victimization experienced over the lifetime, 7 out of 10 young people witnessed or experienced indirect victimization, 1 in 3 experienced property victimization, more than 1 in 4 physical victimization, almost 1 in 2 experienced bullying, 1 in 28 dating violence and 1 in 7 experienced sexual victimization. The findings also suggest that victimization is not an isolated event; participants experienced an average 2.8 different types of victimization across their lifetime. These research findings are compared to those from national victimization surveys in the USA and UK to compile a picture of the victimization prevalence rates across studies. The findings highlight the importance of adopting a holistic approach to the exploration of extrafamilial victimization in future research, assessment of victim experiences, and prevention of extrafamilial victimization.
\end{abstract}

Key words: extrafamilial victimization; community violence; peer victimization; prevalence; poly-victimization; child.

\title{
The prevalence of childhood victimization experienced outside of the family: findings from an English prevalence study.
}


Prevalence of childhood extrafamilial victimization

Young people are vulnerable to violence and abuse from family members, adults, and peers in the home, school and community. Commonly split into two main categories: familybased victimization (intrafamilial victimization) and victimization experienced outside of the family (extrafamilial victimization), research findings have repeatedly shown that victimization within one setting significantly increases the risk of victimization within another (Finkelhor, Ormrod, Turner, \& Holt, 2009; Hong \& Espelage, 2012; Radford, Corral, Bradley, \& Fisher, 2013). However, research has also highlighted distinct differences between intrafamilial and extrafamilial victimization in terms of: the developmental characteristics of victims (Ray, Jackson, \& Townsley, 1991); victimization characteristics (Fischer \& McDonald, 1998); risk factors for and protection against victimization (Black, Heyman, \& Smith Slep, 2001; Fischer \& McDonald, 1998); and the impact of victimization on the young person (Clemmons, Walsh, DiLillo, \& Messman-Moore, 2007).

The research into extrafamilial victimization has risen dramatically since 1990 yet it lags behind that exploring intrafamilial victimization and the majority has been carried out in the United States of America (USA). Knowledge of extrafamilial victimization in the United Kingdom (UK) is, on the whole, based on official reports and small studies focussing on a limited range of experiences. As such, prevalence rates often differ due to differences in definition, survey design and methods (Radford et al, 2013), and there has been a failure to recognise the interconnection between different types of victimization (Finkelhor, Ormrod, Turner, \& Hamby, 2005b). Additionally, limited attention has been given to the characteristics of the perpetrators of extrafamilial victimization against young people, thus limiting our knowledge in this area. As such, more information is needed on the age and gender of these perpetrators, the number of perpetrators who commonly commit each category of victimization, and the relationship between the victim and the perpetrator. 
Prevalence of childhood extrafamilial victimization

Two national victimization surveys carried out in the USA show that $61 \%$ and $71 \%$ of 217 year olds $\underline{(N=2,030 \& N=4,549}$, respectively) experienced some form of victimization within the past 12 months of the survey (Finkelhor, Ormrod, et al., 2005b; Finkelhor, Turner, Ormrod, \& Hamby, 2009), which increased to $87 \%$ for lifetime exposure (Finkelhor, Turner, et al., 2009). This included; child maltreatment, physical victimization, sexual victimization, property victimization, and indirect and witnessed victimization experienced within the family, school and community. In the UK, the National Society for the Prevention of Cruelty to Children (NSPCC) has reported preliminary findings from a similar UK national survey of child maltreatment (see Radford et al., 2011; 2013). Their findings showed that $84 \%$ of the 11-17 year olds in their sample $(N=2,275)$ reported some form of victimization within their lifetime (LT), 57\% within the past year (PY; Radford et al., 2013).

USA and UK findings also suggest that childhood victimization is rarely a one-off event, with children and young people reporting having been victimised, on average, 3.7 to 5 times over their LT (including intrafamilial victimization) (Finkelhor, Ormrod, \& Turner, 2009b; Radford et al., 2013, respectively) and 3 or 2 times in the PY (Finkelhor, Ormrod, et al., 2005b; Radford et al., 2013, respectively). Additionally, a small number of children and young people appear to experience a multitude of different types of victimization on many different occasions by the same or a different perpetrator. These are known as poly-victims and have been found to represent $24 \%$ of young people when looking at PY victimization (Finkelhor, Ormrod, \& Turner, 2007), and 10\% when looking at LT victimization (Finkelhor, Ormrod, \& Turner, 2009a). Of these LT poly-victims, 59\% had experienced victimization at the hands of both family (intrafamilial) and non-family members (extrafamilial).

Further research suggests there may be differences in the individual (age, ethnicity, socioeconomic status, special educational needs, lifetime adversity), familial (parental learning needs, single-parent families) and neighbourhood characteristics of poly-victims compared to 
Prevalence of childhood extrafamilial victimization

lower-level victims (Finkelhor et al., 2007; Finkelhor, Ormrod, \& Turner, 2009b; Radford et al., 2011), yet findings are mixed. Poly-victims also experience the highest level of trauma symptoms compared to non-victimized youth and those with less victimization experiences (Finkelhor, Ormrod, Turner, \& Hamby, 2005a)._Understanding more about this group of young people may help to indicate possible areas for intervention following initial victimization, and help identify those most at risk of repeated victimization.

With a more holistic description of the levels and types of extrafamilial victimization experienced by young people in the UK, schools, communities, families and policymakers may be better informed to make decisions on how to respond to these threats and increase preventative efforts. The current research therefore has three main aims:

1. to investigate the prevalence of extrafamilial victimization amongst a large sample of English young people,

2. to explore the characteristics of the victims and perpetrators of extrafamilial victimization,

3. to investigate the prevalence and characteristics of PY and LT poly-victims. $\underline{\text { The definition of victimization is crucial to a study's findings, and a number of different }}$ definitions have been developed for the various victimization types. The current definition of extrafamilial victimization includes: acts of violence (often referred to as 'community violence'); peer victimization; criminal victimization; dating violence; sexual victimization; and indirect or witnessed victimization (see Appendix 1). This is the same as the definition used in the national surveys by Finkelhor (Finkelhor, Ormrod, et al., 2005b; Finkelhor, Turner, et al., 2009) and Radford et al. (2013), with the exception that all references to family-perpetrated victimization were excluded. However, these definitions may differ to other studies in this area and this should be noted when interpreting and comparing the findings. Of note, the definition of bullying used in the current study includes direct (physical 
Prevalence of childhood extrafamilial victimization

and emotional, including mobile phone and internet harassment) and indirect (relational) forms of bullying, as recommended by Olweus (1991). However, some aspects of relational bullying are not explicitly asked about (e.g., rumour spreading).

Restricting the focus of this paper by excluding intrafamilial victimization means a large proportion of childhood victimization will be ignored. However, the benefit is that a more thorough exploration of extrafamilial victimization can be achieved.

\section{Methodology}

\section{Pilot Studies}

Two independent pilot studies were carried out $(n=27$ and $n=30)$ to test the research procedure and the suitability of, and ability to independently complete, the research measures. These pilot studies informed the decision to use paper copies of all measures instead of electronic versions, due to observed privacy concerns when using computers.

\section{Measures}

Demographic questionnaire. A 28-item questionnaire was developed to collect demographic information. Embedded in this were five 'social desirability' (SD) questions from the 'lie' subscale measure of defensiveness within the Culture-Free Self-Esteem Inventory- Second Edition (CFSEI-2), Form B (Battle, 1993). These questions aim to identify children who are displaying defensiveness or social desirability when answering questions, thus refusing to assign to themselves valid but socially unacceptable characteristics. As such, they may not answer sensitive questions truthfully and they can therefore be screened out of the data set to improve reliability. The subscales on the CFSEI-2 were developed using factor analysis and the measure has been found to demonstrate good reliability and validity (Battle, 1993). This process led to the removal of 133 young people deemed high in SD (i.e., their SD score was higher than the mean plus standard deviation (3.43 out of 5) or they answered all SD questions in a socially desirable way). This decision is supported by findings from chi- 
Prevalence of childhood extrafamilial victimization

square analysis which revealed statistically significant differences between these 130 young people and the 760 who scored low on SD. Those scoring high on SD reported being less likely to be in trouble with the police, having friends who are in trouble with the police, drinking alcohol with friends, and being victimised. Controlling for socially desirable reporting amongst respondents is not mentioned in comparable victimization studies yet the findings of this study suggest $\underline{\text { SD }}$ needs to be considered more widely.

The Juvenile Victimization Questionnaire (JVQ). The JVQ (Finkelhor, Hamby, Ormrod, \& Turner, 2005; Hamby, Finkelhor, Ormrod, \& Turner, 2004) is designed for children and young people aged 8-17 years and has a 34 screening questions which provide a comprehensive assessment of 5 victimization 'modules': conventional crime, child maltreatment, peer and sibling victimization, sexual assault, and witnessing and indirect victimization. Follow-up questions are then used to gain further information on an incident. The scoring of this questionnaire produces a total victimization score, module score (indicating whether a young person has experienced any form of victimization within a module), or category score (to indicate whether the young person has experienced any type of property crime, physical assault, sexual assault or peer and sibling assault). The wording of the questions has undergone extensive testing to maximise comprehension (Hamby et al., 2004) and the questionnaire has been found to have test-retest reliability, construct validity and internal consistency (Finkelhor, Hamby, et al., 2005). Since its development, the NSPCC have adapted this questionnaire for use in the UK with a British sample (Radford et al., 2011) and the current version is matched closely to this to gain comparable UK data.

Current adaptation of the JVQ. The adaptation of the JVQ for the current study included 24 screener questions (excluding questions on intrafamilial victimization) which assessed four of the five modules within the original questionnaire. Two questions on internet and mobile phone victimization from the National Survey of Children's Exposure to Violence 
Prevalence of childhood extrafamilial victimization

(NatSCEV; Finkelhor, Turner, et al., 2009) were also included. Six victimization categories were measured within the current research: property victimization, physical victimization, bullying, dating violence, sexual victimization and witnessed/ indirect victimization (see Appendix 1 for further definition).

Follow-up questions were similar to those in the original JVQ, from which the same questions asking about the perpetrator were used but more were added in. Young people were asked to respond to these questions thinking about the last time something happened to them. Unlike the original questionnaire however, participants were not asked whether the incident disclosed was also part of another incident disclosed in the questionnaire. This was because of the need to reduce the number of follow-up questions and the complexity of the questionnaire to allow for independent completion.

Reliability and validity of the adapted JVQ. The questionnaire was tested for reliability and validity with the current sample (660 participants who answered all JVQ screener questions, excluding those high in SD). Significant weak to moderate positive correlations $(r=.29-.37, p<0.01)$ were found between the aggregate lifetime victimization score and each of the standardised scores on the Trauma Symptoms Checklist for ChildrenAlternate form (TSCC-A; Briere, 1996) subscales, suggesting the measure has construct validity. There was questionable $(\alpha=.66)$ internal consistency for the 24 screener questions and low internal consistency for the module and composite victimization categories (see Table 1). The reliability of victimization categories and construct validity is similar to the original JVQ tested on an American sample, yet the overall reliability of the measure is lower. The reliability and validity of the NSPCCs adaptation of the JVQ is unreported.

\section{---- Insert Table 1 here----}

Calculating victimization scores. Victimization was dichotomised ('victim' yes/ no) based on whether the young person responded positively to any victimization screener 
question. Aggregate LT victimization scores were calculated by summing together the number of screener questions endorsed and PY aggregate victimization scores were calculated for victimization reported to have occurred in the PY. Some young people did not state when the victimization incident happened ('past year', 'over a year ago', or 'both') and the incident was therefore included in LT figures only. Separate scores for direct victimization (14 questions) and indirect victimization (10 questions) were calculated by separating the 24 screener questions into these two categories. The same system was used to classify participants as victims of a particular module or category of victimization, and when assigning an aggregate victimization score for a victimization module or category.

Consistent with previous research (Finkelhor et al., 2009b; Radford et al., 2013), LT polyvictims were defined as young people with the highest $10 \%$ of aggregate LT victimization scores within the sample, which equated to six or more different victimization types.

Following Finkelhor et al's (2007a) method, PY poly-victims were those who scored higher than the mean on aggregated PY victimization scores, which equated to three or more different victimization types.

\section{Sampling and Procedure}

All 36 mainstream schools in one English county (Warwickshire) were invited to take part in the research, of which eight participated (22.2\%). Efforts were unsuccessful to include young people who would be absent from, or underrepresented within, a mainstream school

(e.g., those in marginal societies and pupil referral units). The participating schools consisted of three single-sex and five coeducation schools, of which three were grammar schools and five were community schools (including one Catholic school). The latest English Government Department of Education 'OFSTED' reports prior to the research showed the schools were outstanding $(n=3), \operatorname{good}(n=2)$, and satisfactory $(n=3)$. 
Prevalence of childhood extrafamilial victimization

These schools were all located in an area covered by the 'Safer Schools Partnership' (SSP), an initiative to build closer working relationships between schools and the police (Bowles, Garcia Reyes, \& Pradiptyo, 2005). The principle objectives of the SSP are to: $\underline{\text { reduce victimisation, offending and antisocial behaviour; identify young people at risk; work }}$ with schools on behaviour and discipline; keep young people in full-time education; support vulnerable young people through the transition from primary school to secondary school; and create a safer learning environment (Bowles et al., 2005). Whilst a Police Community $\underline{\text { Support Officer (PCSO) was assigned to each participating school, the schools were not high }}$ priority and the level of PCSO intervention was limited. No specific anti-bullying or victimisation programmes/ initiatives were known to have been implemented, yet school inclusion in the SSP may influence the victim experiences of their pupils.

In five of the schools all of the pupils in years nine and ten (13-15 years) were invited to participate in the project; two schools chose to invite only young people in year nine (aged 13-14); and one school invited only those in year ten (aged 14-15, including one 16 year old). Passive parental consent was gained (with the exception of one school where active consent was requested); parents were sent information and consent letters two weeks and one week prior to the research and asked to return the consent form (using a pre-paid envelope)

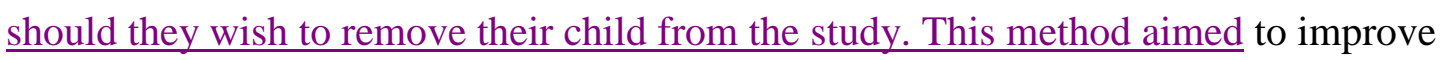
response and participation rates and reduce sampling bias associated with active consent (Hollmann \& McNamara, 1999; Pokorny, Jason, Schoeny, Townsend, \& Curie, 2001). In total, 79 young people out of 2,097 (4\%) did not receive parental permission to participate in the research (active and passive consent combined). Active informed consent was gained from all young people who had parental permission to take part. These pupils were given an information letter and consent form during school 'registration/tutor time' (or equivalent) or 
Prevalence of childhood extrafamilial victimization

the next opportunity. Completed consent forms were collected back from $75 \%$ of pupils $(1,576)$ of whom 1,088 consented to take part $(75 \%)$.

The research was delivered as part of an educational workshop on 'Safety and Victimization' and in most schools this was integrated within their Personal Social Health Education (PSHE) curriculum over one or two sessions. When self-completing the measures, pupils were sat as far apart from each other as was feasible and instructed to work privately and independently. Any safeguarding issues identified by the principle researcher were referred to the Child Protection contact within the collaborating Police Force. Following consultation, the designated Child Protection Officer at the young person's school was then contacted to deal with cases deemed significantly concerning.

\section{Participants}

Due to school absence or a lack of parental consent to take part, 903 young people participated in the research. Those who were absent for one of the two research sessions (if applicable; $\underline{n}=40)$ and/or had a high SD score $(\underline{n}=133)$ were excluded from the dataset. The final sample therefore consisted of 730 participants (35\% of the target population) aged 13 to 16 years (including just one 16 year old, mean 13.8 years, SD 0.72 ) from one UK county. There were more females $(N=471,64.5 \%)$ than males and $3 \%$ of participants responded positively to the question 'do you have a disability'. The ethnicity of the sample was: $89 \%$ White, 1\% Black, 4\% Asian, 5\% 'Mixed', and less than 1\% 'Other'. Disability levels and the ethnic composition of the sample are representative of the Warwickshire county from which it was derived ("Rugby Borough Equality \& Diversity Profile, May 2011 ", 2011). With regards to family composition, $66.7 \%$ of participants reported living with both parents, $16.2 \%$ lived in a single parent household, $13.6 \%$ in a household with a step-parent, $0.3 \%$ with adoptive parents, and 3.3\% lived in 'another' family structure. To measure socio-economic status, pupils were asked whether they were entitled to a free school lunch. However, $31 \%$ of 
Prevalence of childhood extrafamilial victimization

participants answered 'do not know' to this question and only five of the eight participating schools would provide this data, which were generally overall year group figures rather than individual pupil entitlement. Where individual data was given, conflicting information was identified between schools' and pupils' information suggesting this measure of SES is $\underline{\text { unreliable and was thus excluded from any analysis. Nevertheless, as the sample appears to }}$ represent the county it was derived from, it can be estimated that around $10 \%$ of participants were entitled to a free-school meal (free school meal entitlement amongst 5-16 year olds in Warwickshire was 10.2\%; "Rugby Borough Equality \& Diversity Profile, May 2011 ", 2011). $10 \%(N=69)$ of the sample reported having been in trouble with the police and $24 \%(N=$ 174) said they had friends who were at least 'sometimes' in trouble with the police.

\section{Power Analysis and Control Over Clustered Data}

It is important to account for clustering in the data at the school level as schools are likely to have unique characteristics and environmental contexts which may impact on the experiences of pupils. With this clustered data there are two sources of variance; variance within young people within the schools and variability between clusters. As such, there becomes increased variance within any statistical analysis due to the combination of these areas of variance. This will increase standard errors leading to widened confidence intervals and increased p-values, compared to a randomly sampled study of the same size. As such, the sample size is reduced and power is lost (Wears, 2002).

To determine the power of statistical tests (chi-square and t-tests) based on the collected sample size, power analyses were computed using the computer program 'G*Power' (Erdfelder, Faul, \& Buchner, 1996). Alpha was set at .05 for all power calculations and power (1- $\beta$ err prob) was set to 0.80 based on Cohen's minimum suggested power for observational studies (Cohen, 1988). To adjust for clustering within the data, the number of participants calculated by the power analyses was multiplied by the Variance 
Prevalence of childhood extrafamilial victimization

Inflation Factor (VIF; Wears, 2002). Power calculations suggest the current, clustered sample of 730 young people was large enough to detect large effect sizes for the chi-square analyses with one degree of freedom, and medium effect sizes with three degrees of freedom. The clustered data failed to achieve a large or medium effect size for the one t-test carried out.

To account for the use of clustered data within the statistical analyses, adjusted confidence intervals (CIs) are given for all percentages and means. These CIs were first calculated based on the actual sample size and then adjusted to account for clustering by multiplying the confidence interval width by the square root of the VIF. Univariate tests were adjusting for clustering by dividing the chi-square and t-test statistics by the VIF and square root of VIF, respectively (Thompson, Fernald, \& Mold, 2012).

\section{Results}

\section{Prevalence of Extrafamilial Victimization}

Extrafamilial victimization was experienced by the majority of young people over their LT $(84.1 \%)$ and within the PY (67.2\%). Prevalence figures are displayed in Table 2 along with the prevalence of each victimization type. No type of victimization was counted under more than one victimization module or category.

\section{-Insert Table 2 about here-}

As can be seen, conventional crime was the most prevalent aggregate victimization module whilst sexual victimization was the least prevalent. Looking at categories of victimization, bullying was the most prevalent whilst dating violence was the least prevalent.

\section{Offender and Victim Characteristics}

As seen in Table 3, perpetrators are largely known to the victim, with the exception of kidnap/ attempted kidnap which were most commonly perpetrated by a stranger (note, the question asked if the type of victimization was perpetrated by 'someone you know', 'a $\underline{\text { stranger', 'boyfriend/ girlfriend' or 'don't know'. The definition of these relationships was }}$ 
Prevalence of childhood extrafamilial victimization

therefore dependent on the young person's understanding of these terms). For each type of victimization which fell under the category 'dating violence' (see Table 4), the most common perpetrator was the young person's boyfriend.

\section{--- Insert Table 3 here ---- \\ ---- Insert Table 4 here ----}

With the exception of emotional bullying, young people were most commonly victimised by just one other individual (see Table 3 ). There was variation in the age groups of perpetrators according to the type of victimization explored but very few cases were identified in which the perpetrator was younger than the victim.

\section{Gender Differences in the Prevalence and Characteristics of Extrafamilial Victimization}

Chi-square analyses revealed that young males experienced a significantly higher rate of conventional crime than young females over the LT and PY (see Table 2), particularly property and physical victimization. Over the LT, significantly more than double the amount of females reported sexual victimization than young males. No other gender differences were found.

Perpetrator_gender differed according to victim gender and the type of victimization being explored. As seen in Table 5, offences commonly associated with perpetrators who are the opposite gender to the victim (e.g., dating violence and sexual victimization) are more often perpetrated by members of the opposite gender for both males and females.

Additionally, peer victimization was perpetrated more often by members of the same gender. Physical assault and property victimization appear to be perpetrated by males more than females for male victims, yet the perpetrators' gender was mixed for female victims. Insert Table 5 here

\section{Multiple and Cumulative Extrafamilial Victimization}


Prevalence of childhood extrafamilial victimization

The vast majority of victims, $74.9 \%$, were victimised more than once over their LT experiencing, on average, 2.8 different victimization types (e.g., vandalism and emotional bullying) and 2.2 different victimization categories (e.g., bullying and sexual victimization). $\underline{\text { Whilst less }}$ PY victimization was experienced, it was again more common for young people to have been victimised more than once; $61.2 \%$. Young people also experienced 1.7 different types of $\underline{P Y}$ victimization and 1.4 different categories of $\underline{P Y}$ victimization.

Looking at chronic victimization (repeated victimization of the same type/category), young people appear to experience all categories of victimization more than once. Bullying was repeated the most with young people reporting an average of 2.6 experiences over their LT. This was followed by physical victimization (2.2 experiences) and sexual victimization (2.2), dating violence (2.1) and property victimization (1.9).

Poly-victimization. Using pre-defined classification criteria, $14 \%$ of young people $(N$ $=102,95 \% \mathrm{CI}=4.69)$ were classified as LT poly-victims and $23.4 \%$ were classified as PY poly-victims $(N=165,95 \% \mathrm{CI}=7.51)$. Not all LT poly-victims were PY poly-victims and vice versa; in total, $78.2 \%$ of LT poly-victims were also PY poly-victims. Analysis shows poly-victims are significantly more likely to have suffered more serious types of victimization than non-poly-victims (see Table 6). No significant differences were found between the groups in relation to kidnap/attempted kidnap, yet this is likely to be related to its small prevalence within this sample. Differences in the prevalence of contact sexual assault could not be calculated as between-component variance was negative and therefore the VIF could not be calculated to control for clustering.

\section{---- Insert Table 6 here ----}

The demographic characteristics of LT and PY poly-victims were statistically compared to LT and PY lower-level victims (non-poly-victims), yet the groups did not significantly differ on any demographic variable (see Table 7). 
Prevalence of childhood extrafamilial victimization

---- Insert Table 7 here----

\section{Discussion}

\section{Prevalence of Extrafamilial Victimization}

Previous understanding of the prevalence of extrafamilial victimization amongst young people in the UK is largely based on amalgamated data from numerous studies, each focussing on a limited range of victim experiences. This is problematic due to differences in the definition of victimization, methodological techniques, and the population of young people sampled, all of which can influence a study's findings. By conducting a large, schoolbased survey with 730 English young people, the findings from the current study aimed to address this limitation within the research literature. In doing so, the prevalence and characteristics of 24 direct and indirect extrafamilial victimization experiences were explored. This study therefore provides one of the first holistic investigations of the prevalence of extrafamilial victimization amongst a large sample of young people in England. It also explores the characteristics of the perpetrators of extrafamilial victimization, and the prevalence and characteristics of poly-victims, which have been largely neglected in the UK empirical research literature. A large amount of data was collected for this study and the $\underline{\text { themes chosen for analysis in this paper are a non-exhaustive selection of significant findings. }}$

These research findings show that extrafamilial victimization was highly prevalent amongst this English sample of young people (aged 13-16); 8 out of 10 were a victim of some form of victimization over their LT, almost 7 out of 10 were victimised in the past year.

National and international comparisons can be made between these research findings and the Developmental Victimization Survey in the USA (Finkelhor, Turner, Ormrod \& Hamby, 2009) and the NSPCC's study of child maltreatment in the UK (Radford et al., 2013). Exact comparisons cannot be drawn, however, due to the exclusion of intrafamilial victimization from the JVQ in the current study and the way in which some of the victim 
Prevalence of childhood extrafamilial victimization

categories were composed across all three studies. Nevertheless, prevalence rates of LT victimization were very similar; $84.1 \%$ (current study), $83.7 \%$ (NSPCC study), and $87 \%$ (USA survey). This suggests that the vast majority of young people in the UK and USA are victimised in some way during their childhood.

\section{Comparison of UK-Based Research Findings}

Comparing the findings from the current study with those from the NSPCC (Radford et al., 2013), their prevalence rates of indirect exposure to community violence over the LT and PY were lower (61.4\% and 31.2\%, respectively) but close to those reported in the current study ( $70 \%$ and $49.9 \%$, respectively). Rates of 'peer victimization' were higher in the NSPCC's study (LT= 59.5\% and PY=35.3\%) than 'bullying' in the current study (LT=43\% and PY=27\%). However, this may reflect their inclusion of sexual victimization (alongside emotional abuse and physical violence) where this was omitted from the bullying category in the current research. The prevalence of sexual victimization reported by the NSPCC for the 11-17 year old sample ( $\mathrm{LT}=16.5 \%$ and $\mathrm{PY}=9.4 \%)$ was very similar to the current study (14.6\% and $11.2 \%$, respectively) for 13 to 16 year olds. This is in spite of the fact that the NSPCC explored sexual victimization by any perpetrator, including family members, and used a_sample with a wider age-range of young people than the current study. Finally, the figures on dating victimization from the NSPCC survey include sexual victimization, and the prevalence rates reported for their 11-17 year old sample (LT=7.9\% and PY=5\%) were higher than those found in the current study when sexual victimization by a boyfriend or girlfriend was included (5.3\% over the LT). The wider age range of the NSPCC sample (1117 years) may contribute to the increased rate found within this survey as older young people are more likely to be dating and therefore exposed to dating violence than younger people.

Acknowledging the differences between the current study and that of the NSPCC in the inclusion of intrafamilial victimization, the findings from these two UK-based studies 
Prevalence of childhood extrafamilial victimization

suggest that around two thirds of young people in England/ UK experience indirect victimization over their LT and around half experience peer victimization or bullying. Sexual victimization appears to be experienced by around one in six young people over their LT and dating violence was the least common category of victimization, experienced by less than $10 \%$ of young people. Relatively little is known about the impact of witnessed/ indirect extrafamilial victimization on children and young people compared to the impact of other types of victimization. Given the high prevalence of various forms of victimization amongst children and young people in the UK, this is an area that needs further exploration. Whilst intrafamilial victimization has not been explored in this paper, the UK study by Radford et al. (2011) found $21.9 \%$ of $11-17$ year olds to have experienced one or more forms of intrafamilial child maltreatment. Victimization experienced in one setting (e.g., the family) $\underline{\text { was also found to significantly predict victimization in other settings (e.g., 11-17 year olds }}$ $\underline{\text { who had experienced intrafamilial maltreatment were } 1.9 \text { times more likely to be maltreated }}$ by a non-resident adult). Should this form of victimization have been included in the current study, it is likely that the identified victimization rates would have been even higher.

\section{Comparison of UK and USA-Based Research Findings}

Comparing these UK-based findings to those from the USA (Finkelhor, Turner, Ormrod \& Hamby, 2009), rates of physical assault (56.7\% over the LT and $46.3 \%$ in the PY) are higher than in the current study (27.5\% and $16.1 \%$, respectively). However, the USA survey included assault by siblings, peers and others, as well as kidnap/attempted kidnap and dating violence within this category. The prevalence rates for property victimization in the $\underline{\text { USA }}(\mathrm{LT}=37.8 \%$ and PY $=24.6 \%)$ were also higher than those found with the current sample of young people (29.6\% and 16.2\%, respectively), yet the LT and PY prevalence rates for indirect victimization in the USA ( $37.8 \%$ and $25.3 \%$, respectively) were around half those found in the current study (70\% and $49.9 \%$, respectively) and NSPCC research $\underline{(61.4 \% \text { and }}$ 
Prevalence of childhood extrafamilial victimization

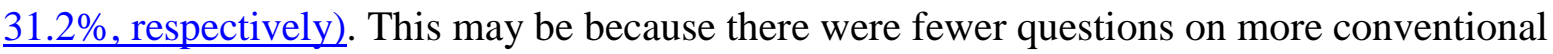
types of witnessed victimization (e.g., bullying) in the USA study, and the inclusion of a wider range of more extreme experiences such as witnessed family violence, gun crime and environmental victimization (e.g., war). Dating victimization within the USA was lower than the UK findings, yet this category excluded emotional dating violence and sexual dating violence which is likely to contribute to this finding. Sexual victimization was also found to be lower in the USA (LT=9.8\% and PY $=6.1 \%$ compared to $14.6 \%$ and $11.2 \%$, respectively), despite this including family members as perpetrators.

In summary, findings suggest that young people in the UK experience higher rates of indirect victimization, peer victimization, dating violence and sexual victimization than young people in the USA. In contrast, figures on property victimization and physical victimization suggest these issues may be more prevalent within the USA.

\section{Gender Differences in the Prevalence of Extrafamilial Victimization}

Exploring the impact of gender on the prevalence of extrafamilial victimization, patterns of victimization suggest gender differences in overall victimization rates are in-line with previous findings in the UK and USA (e.g., Radford et al., 2013, and Finkelhor et al., 2009). Statistical analysis revealed a significantly greater number of young males experiencing conventional crime (LT and PY), including property victimization and physical victimization. However, young females were found to experience significantly more sexual victimization than males. Peer victimization was not found to be significantly different for males and females, yet there were more young females found to have experienced bullying than males, particularly over the lifetime. It is likely that dating violence did not differ between males and females due to its small prevalence in the current sample.

\section{Multiple Victimization}


Previous findings have shown that it is rare for young people to be victimised just once (e.g., Finkelhor et al., 2009b) and the current study supports this. The average number of different LT victimization types experienced by the current sample was 2.8 , ranging from $0-15$. This figure is fewer than those from the USA where an average of 3.7 victim experiences were reported, ranging from 0-26 different types (Finkelhor et al., 2009b). However, a greater number of victimization types were assessed in the USA, including intrafamilial victimization, so this could be expected. It must be noted that participants in the current research were not asked whether the experiences they disclosed within the JVQ were linked to other disclosed victim experiences. Consequently, some of their victimization may be linked (e.g., a robbery which occurred at the same time as, and by the same perpetrators of, a physical assault) meaning the overall extent of victimization may be exaggerated when totalling screener questions (Finkelhor, Hamby, et al., 2005). Nevertheless, this research is able to provide an account of the different types of victimization experienced by the sample.

Together, the current and USA-based research findings suggest that victimization is not an isolated event. The exploration of a young person's victim experiences, be it in a practical or research-based setting, should therefore consider the possibility that the young person has experienced multiple types of victimization. This is particularly so when exploring the impact of victimization on the well-being of the victim.

Poly-Victimization. The current research findings support previous research showing that a small percentage of young people experience a high amount of different victim experiences and can therefore be classified as poly-victims. Poly-victims accounted for $14 \%$ of victims over the LT and $23.4 \%$ in the PY. This is close to the prevalence of LT polyvictimization in the USA (10.2\% - 10.3\% for 11-18 year olds; Finkelhor et al., 2009b), and very similar to PY figures (22\% across all ages; Finkelhor et al., 2007a). This is despite the exclusion of child maltreatment in the current research when it was included in the others. 
Prevalence of childhood extrafamilial victimization

This suggests that around a tenth of the young people in England and the USA experience an extreme amount of extrafamilial victimization over their LT (poly-victimization), rising to around one quarter in the PY. Figures on the prevalence rates of poly-victims have not yet been reported in the UK by Radford et al. (2013)._Finkelhor, Ormrod, and Turner (2009a) found that $59 \%$ of LT poly-victims experienced intrafamilial and extrafamilial victimization, and it is therefore hypothesised that the prevalence of poly-victims in the current study would have been even higher should intrafamilial victimization have been included.

Similar to USA findings (Finkelhor et al., 2007; Finkelhor, Ormrod, et al., 2005a), more poly-victims were found to have experienced the more 'serious' types of victimization than non-poly-victims. Future research should prospectively explore whether poly-victims experience increasingly serious types of victimization over time, or whether poly-victims become more vulnerable to further victimization following an initial extreme victimization episode. In doing so, more could be understood about the developmental pathways towards poly-victimization, including resistance against poly-victimization, in order to develop and improve early intervention. Reporting initial findings, Finkelhor and colleagues (2009) have identified a small number of potentially predictive factors for poly-victimization in an American sample, and further exploration is thus warranted in future UK and USA research.

No statistically significant differences were found between poly-victims and nonpoly-victims in regards to their demographic characteristics (gender, age, ethnicity, disability, and family composition). This is similar to the findings reported by Finkelhor et al. (2009b) for the 11-17 year age group as the only significant difference in their study was that LT poly-victims were less likely to live in intact, two parent family households than LT nonpoly-victims. The findings for PY poly-victimization differed, however, in that Finkelhor et al. (2007a) reported a number of significant demographic differences between PY polyvictims and non-poly-victims whilst the current study reported none. Research findings from 
the current study also differed to those reported with the 11-17 year old sample in the NSPCC study (Radford et al., 2013), whereby PY poly-victims had a higher rate of child and parent disability, were more likely to be older, and had a higher rate of non-victimization adversity. As all three studies used the same classification of poly-victimization, these differences could be sample-specific and/or dependent on the measurement and exploration of the predictive variables. They may also relate to the exclusion of intrafamilial victimization in the current study where this was included, and was a salient feature of polyvictimization, in the NSPCC and USA surveys. It may therefore be the high co-morbidity between intrafamilial and extrafamilial victimization which separates poly-victims from nonpoly-victims. Alternatively, these differences may suggest that the characteristics of polyvictims are not easy to define, and poly-victims may not represent a distinct population of young people. If correct, this would have implications on the effectiveness of preventative efforts to identify poly-victims and prevent young victims from further victimization; an important issue which should be explored further.

\section{Characteristics of Victims and Offenders}

The findings from this study suggest that young people are largely victimised by people they know within the school and the community (with the exception of kidnap/attempted kidnap). However, findings vary slightly according to the type of victimization being explored. With sexual victimization, for example, $65 \%$ of young people reporting contact sexual victimization experienced this at the hands of someone they knew, and $28 \%$ by a boyfriend or girlfriend. Conversely, $44 \%$ of those young people who experienced internetbased sexual harassment were victimised by someone they knew but $43 \%$ were victimised by a stranger. This therefore suggests that young people need to be educated about the risk of violence and abuse from people they know, making a shift away from exclusive worries of 'stranger danger'. However, this should take into account variation in the types of 
victimization they may experience in regards to who they are most at risk from and how they may protect themselves against this (e.g., the dangers of communicating with 'strangers' on the internet).

Whilst around a quarter of young people experienced physical victimization and peer victimization at the hands of a 'gang' (defined as three or more people), the majority of young people were victimised by just one other person across the different victimization types. The age of the perpetrator varied according to the type of victimization being explored. At least half of the physical, sexual and dating victimization experienced by the young people in this study was carried out by people older than them. In particular, kidnap/attempted kidnap and non-contact sexual assaults were largely perpetrated by an older offender $(86.7 \%$ and $71 \%$, respectively). However, young people were asked to simply state whether the offender was 'older', 'younger' or 'the same age' as them and it is therefore unclear as to how much older the perpetrators were. Indeed, the study by Radford et al. (2013) found that $65.9 \%$ of the young people who had experienced contact sexual assault experienced this at the hands of someone under the age of 18. It may therefore be that the offenders in the current study were only a few years older than the victims and is something that should be explored in further research. Indeed, if the majority of perpetrators of victim experiences such as physical assault, sexual victimization and dating violence are most often perpetrated by young people towards young people, then this indicates areas which need to be focussed on in intervention for potential offenders and victims.

\section{Strengths and Limitations of the Research}

The ethnic composition of the current sample was representative of the county (Warwickshire) from which it was taken ("Rugby Borough Equality \& Diversity Profile, May 2011 ", 2011) and largely represents the ethnic composition of England and Wales (whereby $86 \%$ of people are white; Office for National Statistics, 2012). Additionally, the targeted age 
Prevalence of childhood extrafamilial victimization

range of participants (13-15 years) means age should have little influence on the research findings, allowing them to be more reliably extrapolated to this age group. However, this specificity prevents extrapolation of the findings to older and younger children due to developmental effects on victimization (Finkelhor, 2008).

It should also be noted that Warwickshire is not representative of all English counties as it fell within the top third of the least deprived areas in England (Department for communities and local government, English indices of deprivation, 2010), had a lower than average number of lone parents (Office of National Statistics, 2011 Census for the Rugby area (2011); Department for communities and local government, English indices of deprivation, 2010), and faced a third less crime than the average crime rate in England (based on Home Office data for the total recorded crime in England in 2010 to 2011; (Chaplin, Flatley, \& Smith, 2011). The sample also relied on young people attending mainstream schools and who were present on the day of the survey(s), despite attempts to broaden inclusion. The research is therefore likely to under-represent the most vulnerable young people with poor or no school attendance (e.g., pupils in detention units or Pupil Referral Units) or those who do not attend mainstream schools. The research was also carried out in schools which were part of the Safer Schools Partnership and this may have lowered the amount of victimization experienced and perpetrated by pupils. It is likely that the prevalence of victimization will be greater in samples derived from inner-city populations with higher

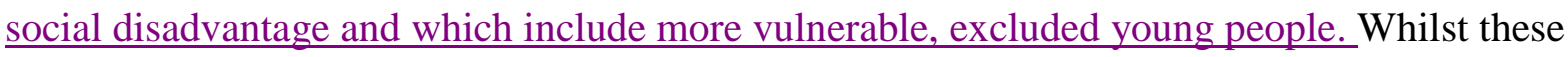
differences_influence the generaliseability of the current research findings at a national level, they make the extremely high prevalence of victimization that was identified even more concerning. It is paramount that further research is carried out with a nationally representative $\underline{\text { sample of English young people, including those excluded from the current study. }}$

Nevertheless, the patterns of victimization found in the current study are largely in agreement 
with those reported by the NSPCC research based on a nationally representative sample of young people in the UK (Radford et al., 2013).

An important limitation of this research is the omission of intrafamilial victimization, thus excluding a potentially large proportion of victim experiences. Consequently, this may explain some of the discrepancies found between this study and the studies by Finkelhor et al. and the NSPCC (Radford et al., 2013), particularly in relation to the characteristics of polyvictims. Comparably high victimization prevalence rates found in this study and these UK and USA national surveys were not anticipated given the exclusion of intrafamilial victimization in the current study. This may relate to the way in which victimization was reported in the current study (self-complete survey within a school setting compared to interviews or computer-assisted interviews in the young person's home) which may have fostered a greater sense of anonymity and thus increased disclosure. The current study also excluded young people responding in a socially desirable way who were found to report lower levels of victimization. The prevalence rates in the current study may therefore be a more truthful reflection of victimization.

\section{Implications of the Research Findings for Practice}

The findings from this study highlight the importance of adopting a holistic approach to the exploration of extrafamilial victimization, assessing the victim experiences of children known to have experienced certain forms of victimization, and working to prevent children and young people from becoming victims. Schools and parents should be alert to the victim experiences of their children in the school and community, and recognise the implications of this for further victimization.

Findings showing that the vast majority of children and young people in this survey, along with others carried out in the UK and USA, fall victim of extrafamilial victimization at some point in their young lives highlight a need for greater preventative efforts. Prevention 
should recognise victimization as a group of connected negative experiences instead of isolating particular areas for intervention (e.g., 'bullying'). Given that many types of extrafamilial victimization are perpetrated largely by known individuals the same age or older, prevention efforts should focus on improving general peer relationships to promote respectful, non-violent interactions, friendships and romantic relations. This would also address the overlap between the perpetration and experience of victimization, which is often noted in the research in this area (Finkelhor, Turner, \& Hamby, 2012).

Turner et al. (2011) recommend that approaches to prevention should include the school and the community and not focus on only one area of the young person's ecology. Indeed, a multifaceted approach towards intervention has been recommended in relation to school and community-based interventions (Kochenderfer-Ladd, Ladd, \& Kochel, 2009; Sieger, Rojas-Vilches, McKinney, \& Renk, 2004). Reviews of the intervention programmes in this area note the necessity of providing multiple disciplines and complementary components throughout intervention, adopting a whole-school approach (Vreeman \& Carroll, 2007), or a community-wide focus. This includes individual support and guidance (Sieger et al., 2004) and involves parents and families as well as young people (Barbero, Hernández, Esteban, \& García, 2012; Ttofi \& Farrington, 2011); altering context without changing individual factors, and vice versa, is limiting (Vézina \& Hébert, 2007).

In conclusion our findings show that adopting a holistic approach to the exploration of extrafamilial victimization reveals that victimization is a common and complex experience among young people. Should these findings be generalizeable to the UK population, there is a need for much greater assessment of victim experiences and the prevention of extrafamilial victimization in schools and communities. 
Prevalence of childhood extrafamilial victimization

\section{References}

Barbero, J. A. J., Hernández, J. A. R., Esteban, B. L., \& García, M. P. (2012). Effectiveness of antibullying school programmes: A systematic review by evidence levels. Children and Youth Services Review, 34(9), 1646-1658.

Battle, J. (1993). Culture Free Self-esteem Inventories: CFSEI-2. Texas, USA.: Pro-Ed, Inc.

Black, D. A., Heyman, R. E., \& Smith Slep, A. M. (2001). Risk factors for child sexual abuse. Aggression and Violent Behavior, 6(2-3), 203-229.

Bowles, R., Garcia Reyes, M., \& Pradiptyo, R. (2005). Safer school partnerships. Youth Justice Board, London.

Briere, J. (1996). Trauma Symptoms Checklist for Children (TSCC): Professional manual. Odessa, FL: Psychological Assessment Resources.

Chaplin, R., Flatley, J., \& Smith, K. (2011). Crime in England and Wales 2010/11: findings from the British Crime Survey and police recorded crime. Home Office: London.

Clemmons, J. C., Walsh, K., DiLillo, D., \& Messman-Moore, T. L. (2007). Unique and Combined Contributions of Multiple Child Abuse Types and Abuse Severity to Adult Trauma Symptomatology. Child Maltreatment, 12(2), 172-181.

Cohen, J. (1988). Statistical power analysis for the behavioral sciences $\left(2^{\text {nd }}\right.$ ed.). Hillsdale, NJ: Erlbaum.

Erdfelder, E., Faul, F., \& Buchner, A. (1996). GPOWER: A general power analysis program. Behavior research methods, instruments, \& computers, 28(1), 1-11.

Finkelhor, D. (2008). Childhood victimisation: Violence, crime and abuse in the lives of young people. Oxford: Oxford University Press.

Finkelhor, D., Hamby, S. L., Ormrod, R. K., \& Turner, H. A. (2005). The Juvenile Victimization Questionnaire: Reliability, validity, and national norms. Child Abuse \& Neglect, 29(4), 383-412.

Finkelhor, D., Ormrod, R. K., \& Turner, H. A. (2007). Poly-victimization: A neglected component in child victimization. Child Abuse \& Neglect, 31, 7-26.

Finkelhor, D., Ormrod, R. K., \& Turner, H. A. (2009a). The Developmental Epidemiology of Childhood Victimization. J Interpers Violence, 24(5), 711-731. doi: $10.1177 / 0886260508317185$

Finkelhor, D., Ormrod, R. K., \& Turner, H. A. (2009b). Lifetime assessment of polyvictimization in a national sample of children and youth. Child Abuse \& Neglect, 33(7), 403-411. 
Prevalence of childhood extrafamilial victimization

Finkelhor, D., Ormrod, R. K., Turner, H. A., \& Hamby, S. L. (2005a). Measuring polyvictimization using the Juvenile Victimization Questionnaire. Child Abuse \& Neglect, 29(11), 1297-1312.

Finkelhor, D., Ormrod, R. K., Turner, H. A., \& Hamby, S. L. (2005b). The Victimization of Children and Youth: A Comprehensive, National Survey. Child Maltreatment, 10(1), 5-25. doi: 10.1177/1077559504271287

Finkelhor, D., Ormrod, R. K., Turner, H. A., \& Holt, M. (2009). Pathways to PolyVictimization. Child Maltreat, 14(4), 316-329. doi: 10.1177/1077559509347012

Finkelhor, D., Turner, H. A., \& Hamby, S. (2012). Let's prevent peer victimization, not just bullying. Child Abuse \& Neglect, 36(4), 271-274. doi: http://dx.doi.org/10.1016/j.chiabu.2011.12.001

Finkelhor, D., Turner, H. A., Ormrod, R. K., \& Hamby, S. L. (2009). Violence, Abuse, and Crime Exposure in a National Sample of Children and Youth. Pediatrics, 124(5), 1411-1423. doi: 10.1542/peds.2009-0467

Fischer, D. G., \& McDonald, W. L. (1998). Characteristics of intrafamilial and extrafamilial child sexual abuse. Child Abuse and Neglect, 22(9), 915-929.

Hamby, S. L., Finkelhor, D., Ormrod, R. K., \& Turner, H. A. (2004). The Juvenile Victimization Questionnaire (JVQ): administration and scoring manual. Durham, NH: Crimes Against Children Research Center.

Hollmann, C. M., \& McNamara, J. R. (1999). Considerations in the Use of Active and Passive Parental Consent Procedures. Journal of Psychology, 133(2), 141.

Hong, J. S., \& Espelage, D. L. (2012). A review of research on bullying and peer victimization in school: An ecological system analysis. Aggression and Violent Behavior, 17(4), 311-322. doi: http://dx.doi.org/10.1016/j.avb.2012.03.003

Kochenderfer-Ladd, B., Ladd, G. W., \& Kochel, K. P. (2009). A child and environment framework for studying risk for peer victimization. In M. J. Harris (Ed.), Bullying, rejection and peer victimization: A social cognitive neuroscience perspective. (pp. 2752). New York: Springer Publishing Company.

Office for National Statistics. (2011). 2011 Census Neighbourhood Statistics: Key Statistics Retrieved 12/05/2014, from http://www.neighbourhood.statistics.gov.uk

Office for National Statistics. (2012). Ethnicity and National Identity in England and Wales 2011 Retrieved 25/7/15, from http://www.ons.gov.uk/ons/rel/census/2011census/key-statistics-for-local-authorities-in-england-and-wales/rpt-ethnicity.html 
Prevalence of childhood extrafamilial victimization

Olweus, D. (1991). Bully/victim problems among schoolchildren: Basic facts and effects of a school based intervention program. The development and treatment of childhood aggression, 411-448.

Pokorny, S. B., Jason, L. A., Schoeny, M. E., Townsend, S. M., \& Curie, C. J. (2001). Do Participation Rates Change when Active Consent Procedures Replace Passive Consent. Eval Rev, 25(5), 567-580. doi: 10.1177/0193841x0102500504

Radford, L., Corral, S., Bradley, C., Fisher, H., Bassett, C., Howat, N., \& Collishaw, S. (2011). Child abuse and neglect in the UK today. London: NSPCC.

Radford, L., Corral, S., Bradley, C., \& Fisher, H. L. (2013). The prevalence and impact of child maltreatment and other types of victimization in the UK: Findings from a population survey of caregivers, children and young people and young adults. Child Abuse \& Neglect(0). doi: http://dx.doi.org/10.1016/j.chiabu.2013.02.004

Ray, K., Jackson, J., \& Townsley, R. (1991). Family environments of victims of intrafamilial and extrafamilial child sexual abuse. Journal of Family Violence, 6(4), 365-374. doi: $10.1007 / \mathrm{bf00980539}$

Rugby Borough Equality \& Diversity Profile, May 2011 (2011). Retrieved from http://www.warwickshire.gov.uk/observatory/observatorywcc.nsf/0/F402CD728A975 1B8802578AF004AB510/\$file/Rugby\%20Profile.pdf

Sieger, K., Rojas-Vilches, A., McKinney, C., \& Renk, K. (2004). The effects and treatment of community violence in children and adolescents: what should be done? Trauma, violence \& abuse, 5(3), 243-259.

Thompson, D. M., Fernald, D. H., \& Mold, J. W. (2012). Intraclass correlation coefficients typical of cluster-randomized studies: estimates from the Robert Wood Johnson Prescription for Health projects. . The Annals of Family Medicine, 10(3), 235-240.

Ttofi, M. M., \& Farrington, D. P. (2011). Effectiveness of school-based programs to reduce bullying: A systematic and meta-analytic review. Journal of Experimental Criminology, 7(1), 27-56.

Vézina, J., \& Hébert, M. (2007). Risk factors for victimization in romantic relationships of young women: A review of empirical studies and implications for prevention. Trauma, Violence, and Abuse, 8(1), 33-66.

Wears, R. L. (2002). Advanced Statistics: Statistical Methods for Analyzing Cluster and Cluster randomized Data. Academic emergency medicine, 9(4), 330-341. 


\section{$\underline{\text { Appendix A }}$}

Definition of the victimization modules, categories, and types used in this research

\begin{tabular}{|c|c|c|c|}
\hline Module & Category & Type & Definition \\
\hline \multirow{6}{*}{$\begin{array}{l}\text { Conventional } \\
\text { crime }\end{array}$} & \multirow{3}{*}{$\begin{array}{l}\text { Property } \\
\text { victimisation }\end{array}$} & Robbery & Had something taken from them by force \\
\hline & & Personal theft & Had something stolen from them \\
\hline & & Vandalism & Had something of theirs broken or ruined \\
\hline & \multirow{3}{*}{$\begin{array}{l}\text { Physical } \\
\text { victimisation }\end{array}$} & Assault & Been hit, kicked or attacked on purpose \\
\hline & & Kidnapping & $\begin{array}{l}\text { Made to go somewhere by someone who } \\
\text { they thought might hurt them }\end{array}$ \\
\hline & & Bias attack & $\begin{array}{l}\text { Hit, kicked or attacked because of their } \\
\text { skin colour, religion, where their family } \\
\text { comes from, physical problem or } \\
\text { sexuality }\end{array}$ \\
\hline \multirow[t]{5}{*}{$\begin{array}{l}\text { Peer } \\
\text { victimisation }\end{array}$} & \multirow[t]{3}{*}{ Bullying } & $\begin{array}{l}\text { Physical } \\
\text { bullying }\end{array}$ & $\begin{array}{l}\text { Been picked on by being chased, had } \\
\text { someone grabbing their hair or clothes or } \\
\text { being made to do something they did not } \\
\text { want to do }\end{array}$ \\
\hline & & $\begin{array}{l}\text { Emotional } \\
\text { bullying }\end{array}$ & $\begin{array}{l}\text { Been called names, people said hurtful } \\
\text { things to them or said they did not want } \\
\text { them to be around }\end{array}$ \\
\hline & & $\begin{array}{l}\text { Internet } \\
\text { harassment }\end{array}$ & $\begin{array}{l}\text { Been bothered, harassed or had mean } \\
\text { words, pictures or videos spread about } \\
\text { them on the internet or mobile phone }\end{array}$ \\
\hline & \multirow[t]{2}{*}{$\begin{array}{l}\text { Dating } \\
\text { victimisation }\end{array}$} & $\begin{array}{l}\text { Dating physical } \\
\text { violence }\end{array}$ & $\begin{array}{l}\text { Pushed, slapped, hit or kicked by a } \\
\text { boyfriend/girlfriend or a date }\end{array}$ \\
\hline & & $\begin{array}{l}\text { Dating } \\
\text { emotional } \\
\text { violence }\end{array}$ & $\begin{array}{l}\text { Been called names, had hurtful things said } \\
\text { to them, or been threatened, controlled or } \\
\text { intimidated by a boyfriend/girlfriend or a } \\
\text { date }\end{array}$ \\
\hline \multirow[t]{3}{*}{$\begin{array}{l}\text { Sexual } \\
\text { victimisation }\end{array}$} & \multirow[t]{3}{*}{$\begin{array}{l}\text { Sexual } \\
\text { victimisation }\end{array}$} & $\begin{array}{l}\text { Internet sexual } \\
\text { harassment }\end{array}$ & $\begin{array}{l}\text { Been asked sexual questions about } \\
\text { themselves, or coerced into talking about } \\
\text { sex when they did not want to using the } \\
\text { internet or a mobile phone }\end{array}$ \\
\hline & & $\begin{array}{l}\text { Contact sexual } \\
\text { assault }\end{array}$ & $\begin{array}{l}\text { Someone has touched their private parts } \\
\text { when they did not want it or had someone } \\
\text { touch their private parts }\end{array}$ \\
\hline & & $\begin{array}{l}\text { Flashing/ sexual } \\
\text { exposure }\end{array}$ & $\begin{array}{l}\text { Been made to look at someone else's } \\
\text { private parts by force or flashing }\end{array}$ \\
\hline \multirow[t]{4}{*}{$\begin{array}{l}\text { Witnessing/ } \\
\text { indirect } \\
\text { victimisation }\end{array}$} & \multirow[t]{4}{*}{$\begin{array}{l}\text { Witnessing/ } \\
\text { indirect } \\
\text { victimisation }\end{array}$} & Burglary & $\begin{array}{l}\text { Had something stolen from their house } \\
\text { which belonged to their family or } \\
\text { someone they lived with }\end{array}$ \\
\hline & & Witnessed theft & $\begin{array}{l}\text { Witnessed someone having something } \\
\text { stolen from them }\end{array}$ \\
\hline & & $\begin{array}{l}\text { Witnessed } \\
\text { vandalism }\end{array}$ & $\begin{array}{l}\text { Witnessed someone having something of } \\
\text { theirs broken or ruined }\end{array}$ \\
\hline & & $\begin{array}{l}\text { Witnessed } \\
\text { physical } \\
\text { bullying }\end{array}$ & $\begin{array}{l}\text { Witnessed someone being picked on by } \\
\text { being chased, having someone grab their } \\
\text { hair or clothes or being made to do }\end{array}$ \\
\hline
\end{tabular}




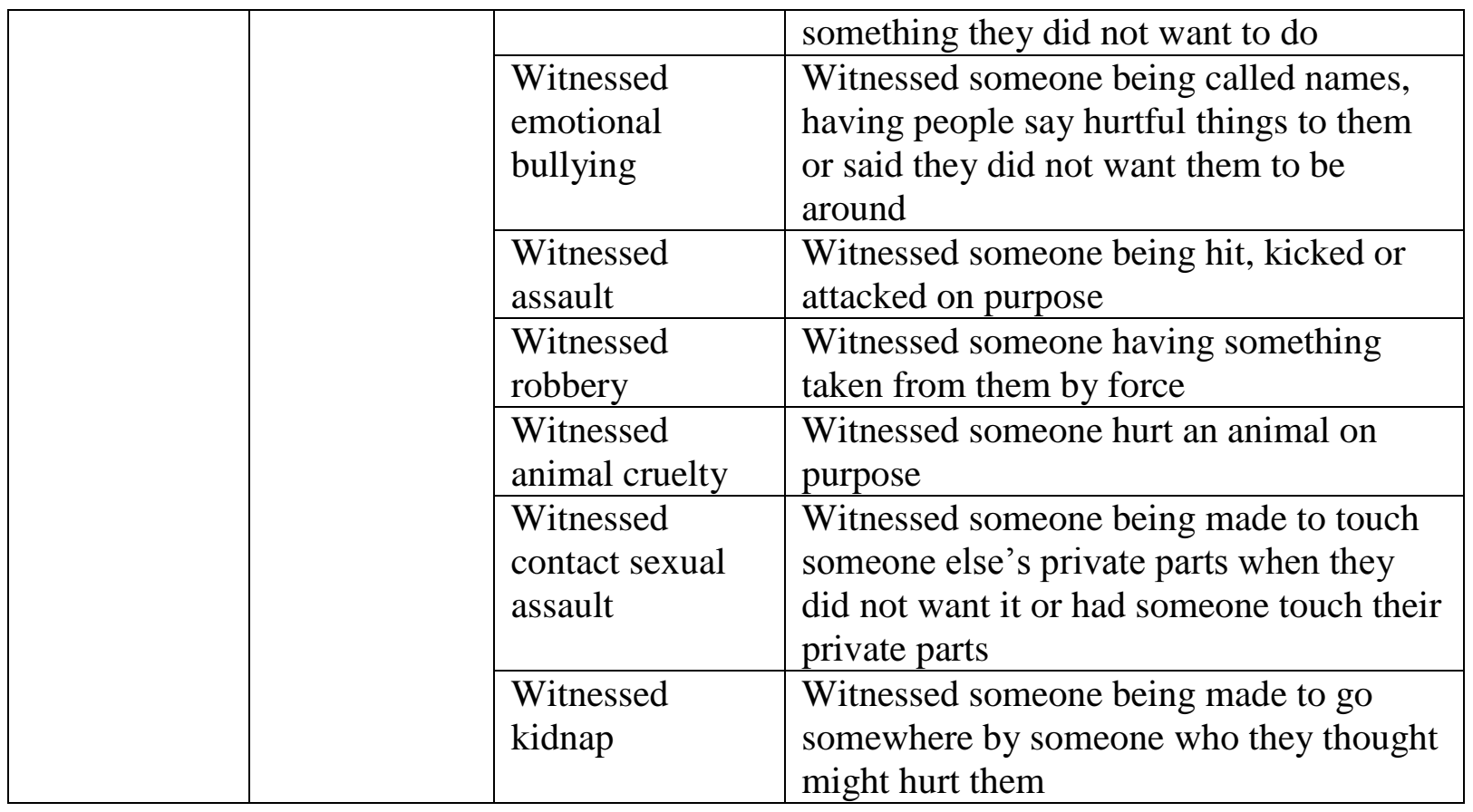

Table 1

Internal Consistency of the Adapted JVQ: Cronbach's Alpha ( $\alpha)$ for the Full Victimization Questionnaire, Victimization Category Scores, and Victimization Module Scores $(N=660)$

\section{Full measure}

Cronbach's Alpha (a)

All 24 victimization screener questions

\section{Victimization module}

Conventional crime

Peer victimization

Sexual victimization

Witnessed/ indirect victimization

Victimization category

Property victimization

Physical victimization

Bullying

Dating violence

Sexual victimization 
Table 2

Prevalence of Lifetime and Past year Childhood Extrafamilial Victimization by Total Exposure, Victimization Modules and Categories

\begin{tabular}{|c|c|c|c|c|c|c|c|c|c|c|c|c|c|c|c|c|}
\hline \multirow{4}{*}{ Victimization Type } & \multicolumn{8}{|c|}{ Lifetime victimization $^{\mathrm{a}}$} & \multicolumn{8}{|c|}{ Past year victimization $^{b}$} \\
\hline & \multicolumn{3}{|c|}{ Total sample } & \multicolumn{5}{|c|}{ Victim Gender } & \multicolumn{3}{|c|}{ Total sample } & \multicolumn{5}{|c|}{ Victim gender } \\
\hline & \multirow[b]{2}{*}{$N$} & \multirow[t]{2}{*}{$\%$} & \multirow{2}{*}{$\begin{array}{l}95 \% \\
\mathrm{CI}( \pm)\end{array}$} & \multicolumn{2}{|c|}{ Male } & \multicolumn{2}{|c|}{ Female } & \multirow{2}{*}{$\chi_{\mathrm{c}}^{\chi^{2}}$} & \multirow[b]{2}{*}{$n$} & \multirow[t]{2}{*}{$\%$} & \multirow{2}{*}{$\begin{array}{l}95 \% \\
\mathrm{CI}( \pm)\end{array}$} & \multicolumn{2}{|c|}{ Male } & \multicolumn{2}{|c|}{ Female } & \multirow{2}{*}{$\chi_{c}^{2}$} \\
\hline & & & & $n$ & $\%$ & $n$ & $\%$ & & & & & $n$ & $\%$ & $n$ & $\%$ & \\
\hline Any exposure & 614 & 84.1 & 6.06 & 224 & 86.5 & 390 & 82.8 & 0.33 & 474 & 67.2 & 8.3 & 182 & 72.5 & 292 & 64.3 & 0.89 \\
\hline Directly victimised & 461 & 63.2 & 6.57 & 182 & 70.3 & 279 & 59.2 & 2.48 & 330 & 46.1 & 7.52 & 137 & 53.5 & 193 & 42.0 & 2.26 \\
\hline Indirectly victimised & 509 & 70.0 & 9.21 & 171 & 66.3 & 338 & 72.1 & 0.35 & 347 & 49.9 & 10.57 & 122 & 49.6 & 225 & 50.0 & 0.001 \\
\hline Conventional crime & 326 & 44.7 & 8.79 & 157 & 60.6 & 169 & 36.0 & $6.94 * *$ & 198 & 27.8 & 8.45 & 110 & 43.5 & 88 & 19.2 & $7.27 * *$ \\
\hline Property victimization & 206 & 29.6 & 6.16 & 102 & 39.4 & 114 & 24.3 & $5.30 *$ & 116 & 16.2 & 5.55 & 62 & 24.4 & 54 & 11.7 & $4.60 *$ \\
\hline Physical victimization & 200 & 27.5 & 7.29 & 102 & 39.5 & 98 & 20.9 & $5.71 *$ & 116 & 16.1 & 6.5 & 67 & 26.2 & 49 & 10.6 & $5.05^{*}$ \\
\hline Peer victimization & 316 & 43.4 & 5.85 & 93 & 36.0 & 223 & 47.4 & 3.34 & 196 & 27.2 & 4.37 & 58 & 22.7 & 138 & 29.6 & 2.17 \\
\hline Bullying & 309 & 43.0 & 5.84 & 92 & 35.7 & 221 & 47.0 & 3.32 & 195 & 27.0 & 4.36 & 58 & 22.7 & 137 & 29.4 & 2.04 \\
\hline Dating violence $^{\mathrm{d}}$ & $25^{\mathrm{d}}$ & $3.4^{\mathrm{d}}$ & 2.49 & 5 & $2.0^{\mathrm{d}}$ & 20 & $4.3^{\mathrm{d}}$ & 0.77 & 14 & 1.9 & 1.34 & 2 & 0.8 & 12 & 2.6 & 1.55 \\
\hline Sexual victimization & 99 & 14.6 & 4.16 & 20 & 7.8 & 86 & 18.3 & $5.66^{*}$ & 81 & 11.2 & 3.72 & 16 & 6.2 & 65 & 13.9 & 3.79 \\
\hline
\end{tabular}

Note: $95 \%$ confidence intervals (CI) and chi-square statistics have been adjusted for clustering. $* p<0.05, * * p<0.01$

${ }^{\mathrm{a}} N=718-730 .{ }^{\mathrm{b}} N=693-728 .{ }^{\mathrm{c}} \mathrm{Gender}$ difference. ${ }^{\mathrm{d}}$ When contact sexual victimization, non-contact sexual victimization, and internet/mobile phone-based sexual harassment are included in the dating violence category (based on information known about the relationship of the perpetrator in regards to the last time each type of sexual victimization happened), the total number of young people reporting dating violence increases to $39 ; 5.3 \%$ of the total sample, $3.1 \%$ males, $6.6 \%$ females; $\chi^{2} 1.17$. 
Prevalence of childhood extrafamilial victimization

Table 3

Characteristics of the perpetrators of childhood extrafamilial victimization

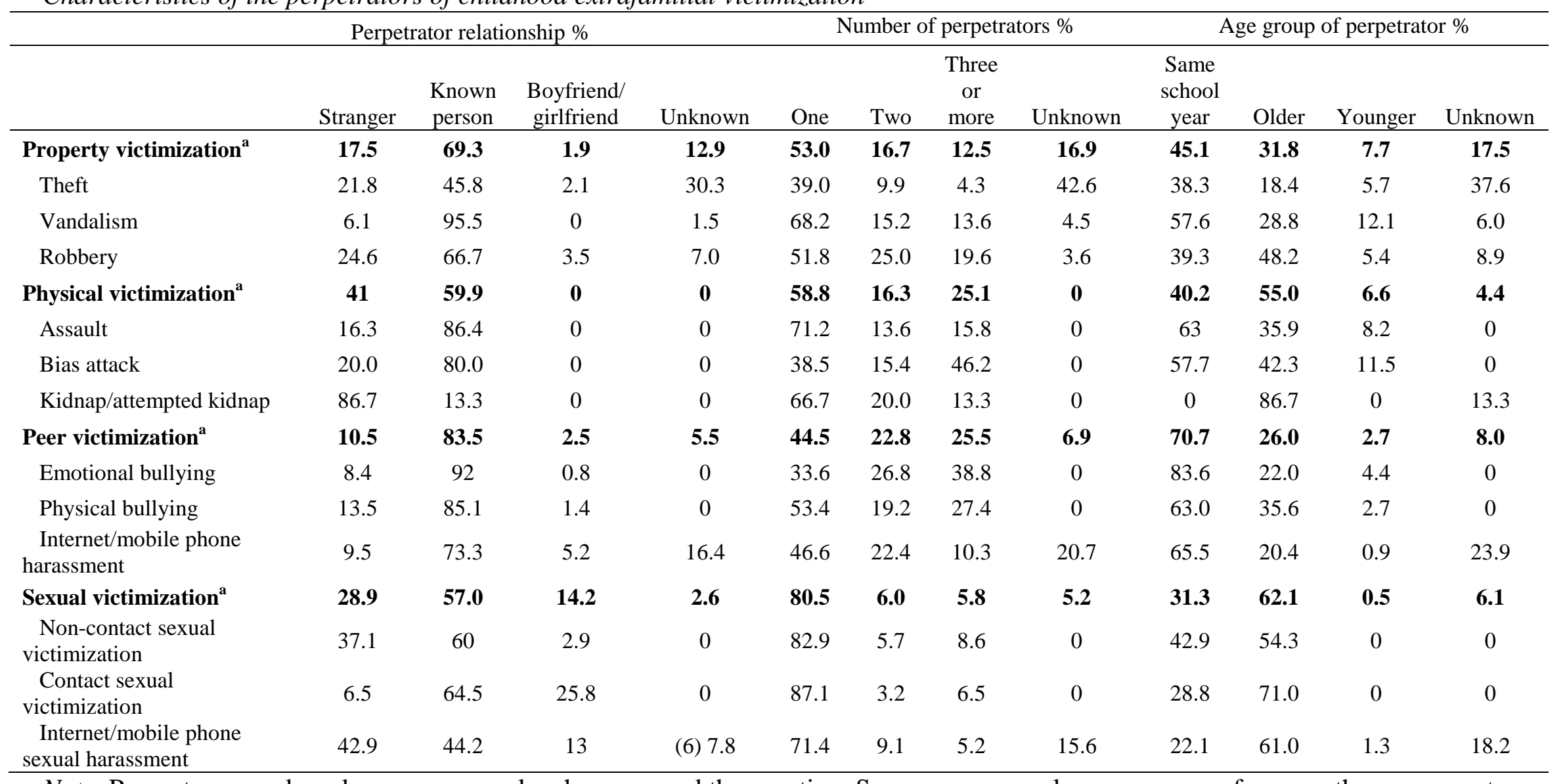

Note: Percentages are based on young people who answered the question. Some young people gave answers for more than one event so percentages may not equal $100 \%$. Questions asking directly about dating violence are not included in this table and are discussed separately in table 4

${ }^{a}$ The percentage for each category of victimization has been calculated by averaging the percentages for the victim types constituting these categories. 
Prevalence of childhood extrafamilial victimization

Table 4

Relationship of the Perpetrator to the victim for each type of victimization under the category 'Dating Violence'.

\begin{tabular}{|c|c|c|c|c|c|c|c|c|c|c|c|c|}
\hline & \multicolumn{8}{|c|}{ Perpetrator relationship } & \multicolumn{4}{|c|}{ Age of perpetrator } \\
\hline & \multicolumn{2}{|c|}{ Boyfriend } & \multicolumn{2}{|c|}{ Girlfriend } & \multicolumn{2}{|c|}{$\begin{array}{l}\text { Male on a } \\
\text { date }\end{array}$} & \multirow{2}{*}{\multicolumn{2}{|c|}{$\begin{array}{c}\text { Female } \\
\text { on a date }\end{array}$}} & \multicolumn{2}{|c|}{$\begin{array}{c}\text { Same school } \\
\text { year }\end{array}$} & \multicolumn{2}{|c|}{ Older } \\
\hline & $\mathrm{n}$ & $\%$ & $\mathrm{n}$ & $\%$ & $\mathrm{n}$ & $\%$ & & & $\mathrm{n}$ & & $\mathrm{n}$ & $\%$ \\
\hline $\begin{array}{l}\text { Dating emotional } \\
\text { violence }(n=18)\end{array}$ & 13 & 72.2 & 3 & 16.7 & 1 & 5.6 & 1 & 5.6 & 9 & 50.0 & 9 & 50.0 \\
\hline $\begin{array}{l}\text { Dating physical } \\
\text { violence }(n=13)\end{array}$ & 9 & 69.2 & 2 & 15.4 & 1 & 7.7 & 1 & 7.7 & 6 & 46.2 & 7 & 53.8 \\
\hline $\begin{array}{l}\text { Contact sexual } \\
\text { victimization }^{\mathrm{a}}(n=8)\end{array}$ & 6 & 75 & 2 & 25 & & & & & 3 & 37.5 & 5 & 62.5 \\
\hline $\begin{array}{l}\text { Non-contact sexual } \\
\text { victimization }^{\mathrm{a}}(n=1)\end{array}$ & 1 & 100 & 0 & 0 & & & & & 0 & 0 & 1 & 100 \\
\hline $\begin{array}{l}\text { Internet/mobile } \\
\text { phone sexual } \\
\text { harassment }{ }^{\mathrm{ab}}(n=10)\end{array}$ & 8 & 88.9 & 1 & 11.1 & & & & & 3 & 30 & 7 & 70 \\
\hline
\end{tabular}

Note: Percentages are based on young people who answered the question and some of the percentages equal more than $100 \%$ as some young people gave answers for more than one event.

${ }^{a}$ Figures on sexual victimization perpetrated by a boyfriend/ girlfriend have been added into this table to provide a more complete overview of dating violence which can be compared with the NSPCC's (Radford et al., 2013) findings. Questions on sexual victimization did not ask whether the perpetrator was a 'male/ female on a date'. Sexual victimization has not been included in the category of dating violence elsewhere. ${ }^{b}$ One young person did not provide information on the gender of the boyfriend/girlfriend. 
Table 5

Gender of perpetrator according to victim gender

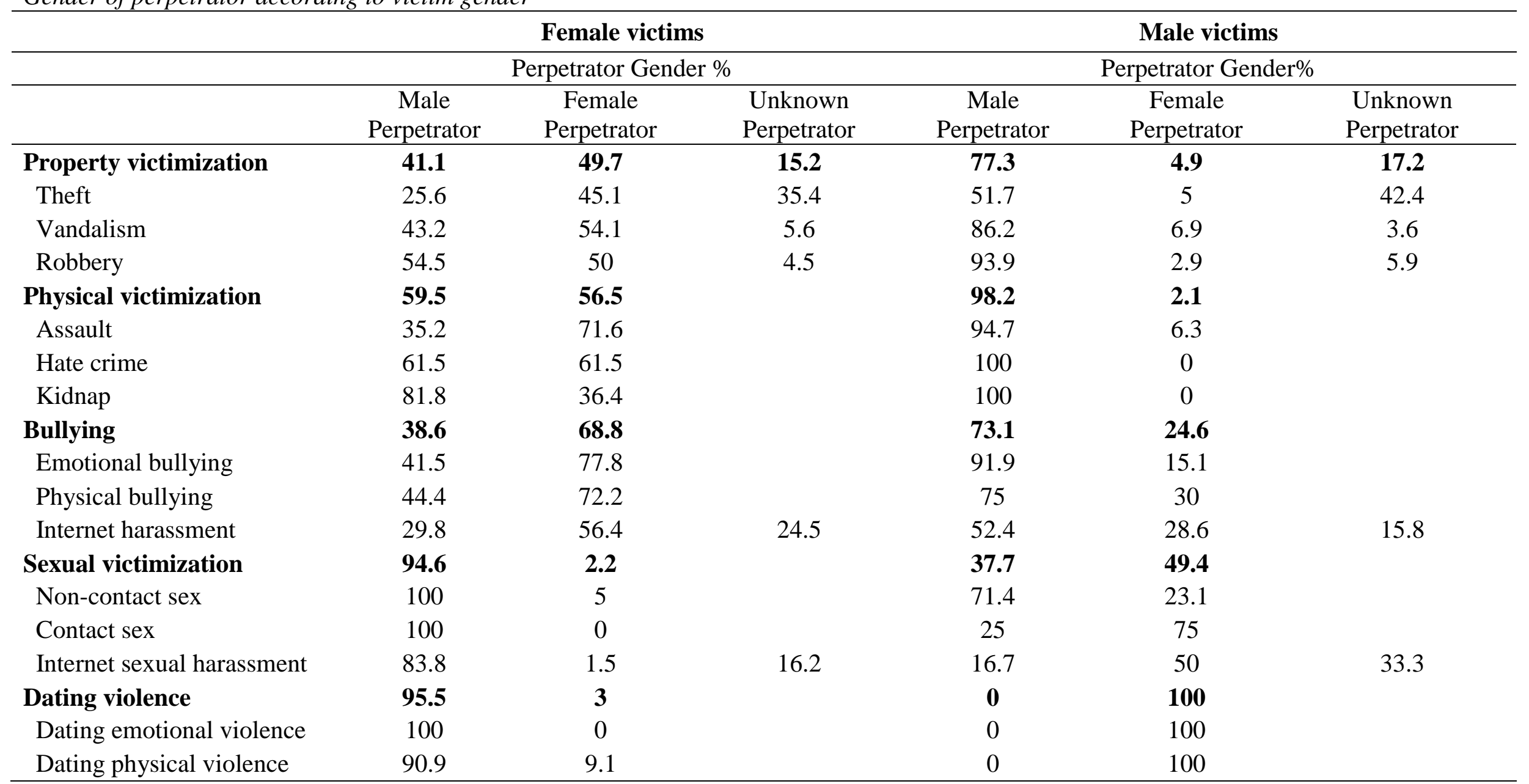

Note: Percentages are based on young people who answered the question. Some young people gave answers for more than one event so percentages may not equal $100 \%$. 
Table 6

Percentage of LT Poly-victims and LT Lower-level Victims (non-poly) Experiencing Serious Types of Victimization

\begin{tabular}{|c|c|c|c|c|c|c|c|c|c|c|c|c|c|c|c|c|c|c|c|c|}
\hline & \multicolumn{10}{|c|}{ Lifetime poly-victims vs. lifetime non-poly-victims } & \multicolumn{10}{|c|}{ Past-year poly-victims vs. past-year non-poly-victims } \\
\hline & \multicolumn{4}{|c|}{ Lifetime victimization } & \multicolumn{6}{|c|}{ Past-year victimization } & \multicolumn{4}{|c|}{ Lifetime victimization } & \multicolumn{6}{|c|}{ Past-year victimization } \\
\hline & \multicolumn{2}{|c|}{ LT victims } & \multicolumn{2}{|c|}{$\begin{array}{c}\text { LT Poly- } \\
\text { victims }\end{array}$} & & \multicolumn{2}{|c|}{$\begin{array}{c}\text { LT } \\
\text { Victims }\end{array}$} & \multicolumn{2}{|c|}{$\begin{array}{c}\text { LT Poly- } \\
\text { victims }\end{array}$} & \multirow[b]{2}{*}{$\chi_{b}^{2}$} & \multicolumn{2}{|c|}{ PY victims } & \multicolumn{2}{|c|}{$\begin{array}{c}\text { PY Poly- } \\
\text { victims }\end{array}$} & \multirow[b]{2}{*}{$\chi_{c}^{2}$} & \multicolumn{2}{|c|}{$\begin{array}{c}\text { PY } \\
\text { Victims }\end{array}$} & \multicolumn{2}{|c|}{$\begin{array}{c}\text { PY Poly- } \\
\text { victims }\end{array}$} & \\
\hline & $N$ & $\%$ & $n$ & $\%$ & $\chi_{a}^{2}$ & $n$ & $\%$ & $n$ & $\%$ & & $n$ & $\%$ & $n$ & $\%$ & & $n$ & $\%$ & $n$ & $\%$ & $\chi_{\mathrm{d}}^{2}$ \\
\hline Assault & 121 & 23.9 & 64 & 64.6 & $14.71 * * *$ & 69 & 13.7 & 41 & 41 & $9.53 * *$ & 96 & 23 & 87 & 53.4 & $13.89 * * *$ & 42 & 10 & 68 & 41.7 & $21.29 * * *$ \\
\hline Bias attack & 11 & 2.2 & 15 & 15.3 & $14.73 * * *$ & 6 & 1.2 & 6 & 5.9 & $5.92 *$ & 12 & 2.8 & 13 & 8.1 & $5.18^{*}$ & 3 & 0.7 & 9 & 5.5 & $8.84 * *$ \\
\hline $\begin{array}{l}\text { Physical dating } \\
\text { violence }\end{array}$ & 5 & 0.8 & 8 & 8.1 & $12.23 * * *$ & 2 & 0.4 & 8 & 7.8 & $17.45^{* * *}$ & 4 & 1.0 & 9 & 5.6 & $8.40 * *$ & 1 & 0.2 & 9 & 5.5 & $13.09 * * *$ \\
\hline $\begin{array}{l}\text { Kidnap/ } \\
\text { attempted } \\
\text { kidnap }^{\text {e }}\end{array}$ & 10 & 2.0 & 5 & 5.1 & 1.10 & 1 & 0.2 & 1 & 1.0 & 1.19 & 10 & 2.4 & 4 & 2.5 & 0.007 & 1 & 0.2 & 1 & 0.6 & 0.32 \\
\hline
\end{tabular}

Note: $95 \%$ confidence interval widths (CI) and chi-square statistics have been adjusted for clustering. ${ }^{*} p<0.05, * * p<0.01, * * * p<0.001(2-$ tailed).

${ }^{a}$ Analysis based on 604-609 participants. ${ }^{b}$ Analysis based on 605-609 participants. ${ }^{c}$ Analysis based on 577-582 participants. ${ }^{\mathrm{d}}$ Analysis based on 581-589 participants. ${ }^{\mathrm{e}} \mathrm{Non}$-significant finding is most likely related to small prevalence rates of kidnap/attempted kidnap.

Table 7

Difference Between LT and PY Poly-victims and Lower-level PY and LT Victims (non-poly-victims)

\begin{tabular}{|c|c|c|c|c|c|c|c|c|c|c|}
\hline & \multicolumn{2}{|c|}{ LT Victims } & \multicolumn{2}{|c|}{ LT Poly-victims } & \multirow[b]{2}{*}{$\chi^{2 \mathbf{a}}$} & \multicolumn{2}{|c|}{ PY victims } & \multicolumn{2}{|c|}{ PY poly-victims } & \multirow[b]{2}{*}{$\chi^{2 \mathrm{~b}}$} \\
\hline & $n$ & $\%$ & $n$ & $\%$ & & $\boldsymbol{n}$ & $\%$ & $n$ & $\%$ & \\
\hline Male & 194 & 37.9 & 30 & 29.4 & 0.12 & 124 & 40.1 & 58 & 35.2 & 0.05 \\
\hline White & 456 & 89.6 & 88 & 86.3 & 0.57 & 276 & 89.9 & 146 & 88.5 & 0.14 \\
\hline Disability & 12 & 2.4 & 3 & 3.0 & 0.11 & 7 & 2.3 & 6 & 3.7 & 0.59 \\
\hline Family composition $^{c}$ & & & & & 2.29 & & & & & 4.95 \\
\hline Age (mean) $)^{\mathrm{d}}$ & 13.82 & & 13.76 & & 0.18 & 13.83 & & 13.76 & & 0.22 \\
\hline
\end{tabular}

${ }^{\mathrm{a}}$ Analysis based on 562-614 participants. ${ }^{\mathrm{b}}$ Analysis based on 426-474 participants. ${ }^{\mathrm{c}}$ One $2 \times 4$ chi-square was carried out to explore differences across the four 'family composition' categories (both biological parents, single-parent family, step-parent present, 'other'). ${ }^{\mathrm{d}}$ This analysis was based on a T-Test (adjusted for clustering), and not Chi-Square. 